Article

\title{
Playing God
}

\section{Uwe Meixner}

Institute of Philosophy, University of Augsburg, Universitätsstr. 10, 86159 Augsburg, Germany; uwe.meixner@phil.uni-augsburg.de

Received: 9 February 2019; Accepted: 15 March 2019; Published: 19 March 2019

check for updates

\begin{abstract}
Metaphysical modelling is a method in (epistemologically enlightened) metaphysics. It uses models for the philosophical analysis of metaphysico-epistemological situations. In this paper, the method is applied to a set of metaphysical questions that concern the relationship between God and the world, and the relationship between human beings and the world. The questions revolve around a center: What is it that ultimately determines reality? This complex metaphysical subject is treated in a simplified and downsized manner: on the scale of board games. As will be seen, the unusual perspective provided by the model leads to new insights and has a salutary corrective effect in the metaphysico-epistemological respect. The paper also provides an analysis and defense of analogical thinking in metaphysics (of which way of thinking metaphysical modelling is a special form).
\end{abstract}

Keywords: metaphysical modelling; analogy and analogs (models); board games, as types or tokens, as abstract or concrete, as actual or merely possible; laws and rules; nomological determination; chance and choice; free will; immanence and transcendence; limits of reason; Kant; epistemologically rational possibility; players and makers; creation; miracles; metaphysical naturalism; God

Metaphysical modelling is a method in philosophy that seeks to draw conclusions about a large and complex metaphysical situation from a small and simple model of it. In metaphysical modelling, metaphysics turns into the metaphysics of a model, with the aim that the metaphysics of the model will, in projection, tell significant truths about the metaphysics of what is being modelled: about the "real" metaphysics of "the real thing." ${ }^{1}$ Metaphysical modelling —an indirect method-is the method chosen here because dealing directly with the relevant large and complex metaphysical situation itself has proven to be exceedingly difficult for human intelligence (at least in my view); it has rather tended to lead to epistemological self-deceptions.

The crucial issue in an application of metaphysical modelling is, of course, whether the downsizing and simplification involved in this method preserves what is essential, or, on the contrary, disfigures, distorts, even eliminates it; in other words, the crucial issue is whether or not a given metaphysical model is a good analog (or simulacrum) of a given metaphysical situation. Whether this is so or not has to be decided from case to case (there does not appear to be any general argument against the possibility of metaphysical modelling).

In metaphysical modelling, two different orders of procedure can be observed: either one first presents the metaphysical situation and then proceeds to its model, or one first presents the model and then proceeds to the situation it models. It seems to me that the illuminative effect of metaphysical modelling is greater if the second-mentioned order of procedure is the one observed. At least this seems to be the case if readers are kept, in a sufficient measure, from losing patience: by being given a preliminary indication of "what all this is good for," "why we are being told all this." In what follows, I will do metaphysical modelling of the "first the model, then what is modelled" type. And what is the

1 For a comprehensive exposition and application of the method, see (Meixner 2010). 
point of my descriptions and distinctions? They amount to presenting a model of the metaphysical (or metaphysico-epistemological) situation we find ourselves in if we inquire into the relationship between God and the world (which involves the very question of God's existence), and into the ultimate (hence metaphysical) nature of the relationship between $u$ and the world.

\section{Board games}

A board game qua type is an abstract structure with six features:

1. with a board (in abstracto) and a specific arrangement of finitely many positions on it;

2. with a non-empty finite set of pieces (in abstracto); the pieces may all be intrinsically different from one another; it may also be the case that all or some of them are intrinsically identical, yet different from each other: different only "by number," "numerically";

3. with at least two discrete successive game stages, that is, with at least the first game stage and the second; there may, of course, be many more successive game stages than merely these two; however, their number has to be finite;

4. with a non-empty finite set of possible initial states (consisting in some or all of the pieces being placed at certain positions on the board);

5. with a non-empty finite set of transition-rules, regulating how the given positions and/or number of the pieces on the board-in short: a state of the board — can be modified in making a transition from one game stage to the next;

6. with a non-empty finite set of possible terminal states.

A board game qua abstract token is a possible abstract instantiation of a board game qua type: One of the possible initial states fills the first game stage (perhaps only one initial state is possible), being followed at the second game stage-in compatibility with the transition-rules-by another (or the same) state of the board, followed (likely enough) at the third game stage by another (or the same) state of the board, and so on, always in compatibility with the transition-rules, until every game stage is filled by a state of the board-or the game ends by running into a possible terminal state.

A board game qua concrete token is just like a possible abstract instantiation of a board game qua type, except, first, for the fact that the board and the pieces are embodied by a concrete (non-abstract) board and by concrete (non-abstract) pieces, and that the positions on the board and the states of the board are accordingly transformed: from abstract to concrete; and except, second, for the fact that the game stages are embodied by concrete intervals of time. It should be noted that the concreteness of the states of the board together with their concrete durations throughout concrete intervals of time does not (logically) entail that the states of the board are physical, let alone material. And it does not entail that they are actual. In an actual board game qua concrete token, the game stages are embodied by intervals of actual time, throughout each of which a concrete state of the board is actual.

The following may serve for illustration: A Chess game Spassky and Fischer actually played is an actual board game qua concrete token; a Chess game Spassky and Fischer did not actually play but might have played on a concrete board (whether that board is actual or not) with concrete pieces (whether they are actual or not) is not an actual board game qua concrete token, though it is still (simpliciter) a board game qua concrete token. A round of Chess that a Chess-theoretician abstractly envisages and abstractly describes is an actual board game qua abstract token, and the game of Chess itself is an actual board game qua type (it is actually because it has actual instantiations, abstract and concrete ones).

It is possible (that is, it is not outright unreasonable) to believe that every board game qua type and every board game qua abstract token is actual (an actual being) - and would be actual even if there were no intelligent beings in the universe. This belief is simply the result of applying Platonism-in other words, (extreme) realism about abstract entities-to board games qua types and to board games qua abstract tokens. It is also possible (not outright unreasonable) to believe that any board game qua 
concrete token, whether it is actual or not, could be actual even if there were no intelligent beings in the universe. Might it not play itself (so to speak), automatically?

This said, it must be emphasized that the no-intelligence-is-necessary view about the actuality of board games is implausible. We rather tend to believe-and for good reason-that not every board game qua type and not every board game qua abstract token is actual, and that those board games qua type or abstract token which are actual, are actual only because they have intelligent inventors, and would not be actual without being invented by such inventors. We also rather tend to believe that every actual board game qua concrete token is actual only because it is played by intelligent players, ${ }^{2}$ and that it would not be actual without being played by such players. Both beliefs seem true to me. But now, no matter whether they are true or not: If I were asked to invent a board game qua type which sells well on the market for board games and is played by many people, what would be good general advice for me?

\section{Advice for inventors of board games}

There is one entirely general advice: Make it interesting! What is meant by "interesting" here? The answer is clear enough: The board game (qua type) when played-that is, when an instantiation of it is actualized by one or more players-should not be boring to the players: it should, when played, provide a sufficient amount of play-excitement to them-which cannot be had without its having, when played, a sufficient amount of play-importance for them. Note that an interesting board game may be intellectually challenging, but it certainly does not have to be intellectually challenging in order to be interesting: there are interesting board games pre-school children no less than grown-ups have great fun with. What is it, then, that makes a board game interesting? What is it that gives to it, in the eyes of the players, a sufficient amount of play-importance? Is there a globally true answer to these questions - an answer that is valid for all interesting board games?

There is. The answer emerges in the most convincing way by approaching it gradually from the negative side: by considering, in a general manner, uninteresting board games (qua types), in other words, board games which are, on the whole, for their players without sufficient play-importance and, therefore, without sufficient play-excitement.

The most uninteresting kind of board game is this: There is only one possible initial state, and for every game stage after the first, the transition-rules uniquely determine the state of the board at that game stage. Somewhat less uninteresting, but still decidedly uninteresting is the following kind of board game: There are several possible initial states, but for every game stage after the first, the transition-rules uniquely determine the state of the board at that game stage.

What makes these two kinds of board game uninteresting is their determinism: complete determinism in the first case, mere transition-determinism in the second. Board games of either one of the two deterministic kinds give their players nothing, or next to nothing, to do-that is, to do in the full sense, which means: to determine — as actual — by their own choice (within the limits of the game, of course) what is (as yet) undetermined. If it is not entirely obvious from the transition-rules how the game will progress after its initial state-that is, after the uniquely possible initial state, or after the initial state selected from the pool of possible initial states-then a deterministic board game may still be of mild - in exceptional cases even of considerable-interest; but it can have an interest only for spectators, not for players.

In order to be interesting (for players), a board game has to be not only non-deterministic, it must also be indeterministic; that is, its transition rules must be such that they do not usually (and not only: not always) determine the state of the board at the next game stage. If a board game is indeterministic

2 Deep Blue, too, and its likes are intelligent players, although their (unconscious) intelligence is-in its entirety-given to them by human programming. Artificial intelligence is a borrowed (and unconscious) intelligence. That some intelligent machines are able to learn does not controvert this verdict, since the learning they do follows the lines pre-established by human programming, exclusively those lines. 
(in this sense) but has a uniquely determined initial state (as in the case of Chess) then its interest for players may still be very great (as is the case with Chess). A maximum of player-choice, however, is provided by indeterministic board games which have many possible initial states and where the choice of which of these states is to be actual is up to the player(s); an example for such a board game is Go.

If a board game is indeterministic, then this does not make it anarchic. In an indeterministic board game the transition-rules do not usually determine the progress of the game, but they nevertheless rule it: they provide the (more or less wide) framework within which the players can make their choices of game-token actualization.

These choices can be made in two ways: with the help of chance (perhaps even to the point of chance being wholly "responsible" for the choice) or without it. A board game is a pure game of chance if, in playing it, all of the choices of game-token actualization are wholly due to chance. In contrast, a board game is a pure game of deliberation if, in playing it, all of the choices of game-token actualization are wholly due to the deliberation of the player(s). Between these two extremes, all manners of the combination of chance and deliberation in game-token actualization are conceivable. ${ }^{3}$ Inventors of board games are advised that the inclusion of a significant amount of chance in game-token actualization makes a board game accessible to a wider range of potential players and dramatically increases its recreational effect (its "fun"). More importantly, the inclusion of a significant amount of chance in game-token actualization reduces—and may nullify—-the intellectual inequality between the players of antagonistic board games, making such board games more—or entirely—just. In the playing of such board games, it reduces-and may nullify (that is, nullify under rational consideration) - the pride of the winners and the humiliation of the losers. Indeed, in an antagonistic pure game of chance, there is, rightly considered, only one player: chance (the other so-called "players" are merely its instruments: whether they win or lose, it is neither their merit nor their fault).

What may be the reason for the fact that only indeterministic board games are interesting, that, therefore, only indeterministic board games sell well? The answer is simple: Only indeterministic board games are lifelike. How unlike the lives of their players they may be in other respects, indeterministic board games preserve a central characteristic of being in the world: contingency, apparent as chance and choice in every moment of conscious life. Are these appearances really just illusions-as many philosophers firmly believe-and without metaphysical significance? Determinists who are also inventors of board games may have- they ought to have-second thoughts. (Unfortunately, there do not seem to be many determinists who are also inventors of board games.)

\section{Immanence and transcendence with regard to board games}

Consider some actual board game qua concrete token, one played by two players who "have fun" in doing so. For ease of reference, let us call this board game " $g$ "; $g$ is, precisely, an actual temporal sequence of actual states of the board, each state lasting an actual interval of time, each state involving the same actual and concrete board with the same actual and concrete positions, and whatever pieces are in some manner located there (perhaps not always the same pieces); those pieces, too, are actual and concrete. All of this actuality belongs to the immanence of $g$, which totality of actuality is nothing else than $g$ itself. However, there are, of course, "items" beyond $g$ (beyond the immanence of $g$ ): $g$ is embedded in-is, in fact, a part of-a much larger actuality: the whole of actuality, the actual world; and going beyond the actual world, $g$ is also a part of the whole of possibility, of so-called "logical space," and going beyond that-whether there really is something beyond logical space, or not— $g$ is a part of the whole of being. The totality of being beyond $g$ is the transcendence of $g$. Thus, the immanence of $g-g$ itself-is encompassed by (but not a part of) the transcendence of $g$; together, they are the whole of being.

3 Note that Chess is not-is not quite-a pure game of deliberation, and that Aggravation (for example) is not a pure game of chance. 
There are two fundamental truths about the relationship between the immanence and the transcendence of $g$ : (1) The inventor of the board game qua type $\Gamma$ ("Gamma"), of which $g$ is an actual and concrete instantiation (or: actual and concrete token), $\Gamma$ itself, and the definition of $g$ as the game it is (in other words: the essence of $g$, which makes it a token of $\Gamma$ ), and whoever made the pieces of $g$ and the board of $g$ with its pattern of positions, and, finally, the two players of $\Gamma$ who take the final steps towards making $g$ actual, towards actualizing $g$-all this belongs to the transcendence of $g$. (2) The immanence of $g$ does not reveal much about the transcendence of $g$. Indeed, the facts that are of the highest ontological relevance with regard to $g$ - to its actuality-are epistemically inaccessible or accessible only in a very small measure from within the immanence of $g: g$, in itself, ${ }^{4}$ does not reveal who made its board and pieces, and who is the inventor of the board game (qua type) $\Gamma$ of which $g$ is an actual and concrete instantiation, and who are the two players that actualize $g$ by playing $\Gamma$; it does not tell what their nature is, let alone how their minds work; most importantly, $g$, in itself, does not reveal of which board game qua type, precisely, it is an actual and concrete instantiation: though a few things about $\Gamma$ can be known from $g$, $\Gamma$ cannot be known from $g$.

How very little can be known about $\Gamma$ by merely looking at $g$ can be gathered from the following considerations. $\Gamma$ can be represented fairly adequately by the set $\mathrm{M}(\Gamma)$ of all canonical abstract instantiations of it. ${ }^{5}$ Since the two players "have fun" in producing $g$, in other words: in playing $\Gamma$ (thereby-in a secondary sense-playing $g$ ), $\Gamma$ must have a sufficient amount of play-importance for them when being played, which means (compare Section 2) that $\mathrm{M}(\Gamma)$ must have many, many elements. But $g$ corresponds to only one of the many elements of $\mathrm{M}(\Gamma)$ - and so does each of its replays: each of its actual or possible repetitions with the same concrete equipment; they each correspond to the very same element of $\mathrm{M}(\Gamma)$ that $g$ corresponds to. From $g$ we learn about one possible initial state of $\Gamma$; we do not learn from $g$ whether $\Gamma$ also has other possible initial states, and if so, which states they are. From $g$ we learn about one sequence of states of the board which is possible (that is, allowed) in $\Gamma$; we do not learn from $g$ which other sequences of states of the board are possible in $\Gamma$; in fact, we do not learn from $g$ whether, beside $g$, any other sequence of states of the board is possible in $\Gamma$. For all we know from $g$ alone, $\Gamma$ may be a deterministic board game; and for all we know by merely considering $g$, $\Gamma$ may, in fact, be deterministic in the following bizarre (because highly uneconomic) way: it prescribes, in detail, precisely one initial state, and for each game stage after the first, its transition-rules (if one still wants to call them "transition-rules") prescribe, in detail, precisely one state of the board at that stage without referring in the least to the previous game stage or stages. On the other hand, for all we know from $g$ alone, $\Gamma$ may also be maximally indeterministic: it may be a board game (qua type) such that every in itself possible state of the board (that is, every possible positioning of some, or all, or no pieces on the board) is a possible state of the board at every game stage, no matter what went before.

If it turned out that our ambition and aspiration is to acquire knowledge about $\Gamma$ : a board game wholly unknown to us so far, would it worry and faze us-perhaps throw us into epistemological despair - that so little can be known about $\Gamma$ by looking at $g$ ? No, not at all. Why? Because, with regard to $g$, we have the God's-eye point of view. We belong to the transcendence of $g$, and it is (normally) fairly easy for us to learn, in full detail, of which board game $\Gamma$ (qua type) $g$ is an actual and concrete instantiation, thereby coming to understand the full meaning of what the two players, who are producing $g$, are doing, thus also coming to understand their absorption with what they are doing (they "have fun," we assumed).

4 The tag "in itself" is important: one might imprint any amount of information on the board of $g$, but this information is not an intrinsic part of $g$, of this actual board game qua concrete token; it is something superadded to $g$.

5 In other words: For representing $\Gamma$ fairly adequately one need not resort to all possible abstract instantiations of $\Gamma$; it suffices to consider all-in a certain way-canonical abstract instantiations of it. The representation of $\Gamma$ by $M(\Gamma)-$ or by any other full set of (in a certain way) canonical abstract instantiations of $\Gamma$-is only fairly adequate because the transition-rules of $\Gamma$ can be read off $\mathrm{M}(\Gamma)$ — can be determined from $\mathrm{M}(\Gamma)$ —only in a specificity that goes no further than logical equivalence: no differentiation between logically equivalent formulations of the transition-rules is possible merely on the basis of $\mathrm{M}(\Gamma)$. 


\section{Chess-White and Chess-Black, and their speculations}

For what follows, it is better to connect a more specific idea with $g$ than has so far been connected with it; so let $g$ be an actual Chess game qua concrete token. Moreover, let us somewhat broaden the immanence of $g$, so that $g$ becomes a proper part of the immanence of $g$, and is no longer identical to it. In what manner, precisely, is this broadening of the immanence of $g$ effected? As follows: Imagine that the white pieces of $g$ constitute a conscious intelligent organism, of which the white king is the vital center (its brain, if you like); call this organism "Chess-White." Imagine, likewise, that the black pieces of $g$ also constitute a conscious intelligent organism, of which the black king is the vital center; call this other organism "Chess-Black." Chess-White and Chess-Black find themselves engaged in a struggle, each trying to checkmate the other, that is, to render the other permanently motionless. Looked at from the outside (that is, regarded from the point of view of the transcendence of $g$ ) what Chess-White and Chess-Black are doing in this struggle-and what they are doing is in its entirety documented in $g$-perfectly conforms to the definition to "the rules" of Chess (qua type). But looked at from the inside - that is, regarded from the point of view of the broadened immanence of $g$ - how does it look? How, in other words, does what they are doing look to Chess-White and Chess-Black themselves?

Chess-White and Chess-Black do not quite have the perspectives of two opponent players of Chess, although their perspectives are somewhat similar to those perspectives. When his turn to make a move comes and the struggle is not yet at its end, the protagonist (that is, the agent whose turn it is: Chess-White or Chess-Black) invariably finds himself moving one (or perhaps two) ${ }^{6}$ of his limbs, i.e., one (or two) of the white pieces; or one (or two) of the black ones. He is doing so, as is perfectly clear to him, after an evaluation of the complete situation given on the board and in accordance with his will, which aims to checkmate the antagonist (at least at first; later, the aim may merely be to achieve a draw). When his turn to make a move comes and the struggle is not yet at its end, the protagonist, after a certain time of deliberation, invariably finds that he wills a certain (local) change of the (total) position of his limbs (which may also involve the removal of one of the limbs of the antagonist, or the transformation of a less valuable limb of his own into a more valuable one)-and the willed change is invariably found to happen "obediently" (just as willed). Moreover, on most occasions of its being his turn to make a move, the protagonist believes of many changes of the position of his limbs that he could will any single one of these on the given occasion, and that it would happen if he willed it. On all such occasions, however, he also believes of many changes of the position of his limbs that they would not happen even if he willed them on the occasion. As it happens, all of these beliefs are true beliefs and in perfect conformity with the rules of Chess-of which game neither Chess-White nor Chess-Black have any idea; for them, their struggle is a perfectly serious matter, a matter of "life and death," so to speak. Both Chess-White and Chess-Black believe that there are occasions where there is only one change of the position of limbs that would happen if the protagonist willed it: the one he, in fact, wills; both Chess-White and Chess-Black also believe that there are occasions where there would be no actualized change of the position of limbs forever, no matter which change is willed. Indeed, in perfect conformity with the rules of Chess (unbeknownst to them), they know (that is, correctly identify) which occasions those occasions are (or would recognize them as soon as being confronted with them). They each consciously try to avoid being confronted by the opponent with an occasion of permanent immobility, and they each consciously try to confront the opponent with an occasion of permanent immobility - which would end the struggle and decide who is the winner and who is the loser. They also know that all of this trying may become pointless for both sides, and on which occasions it would definitely be pointless; on those occasions, they would simply stop the struggle, without winner and without loser. And what happens to Chess-White and Chess-Black after the struggle? Let's assume they simply die (that is, they cease to be conscious) - the winner happily,

6 In a castling, two pieces (of the same color) are moved. 
the loser unhappily, and if the struggle ended with a draw, both die in a neutral state of mind; let's assume both are aware of "their final fate."

The stream of the particular states of consciousness that concern the progress of $g$ (that is, the progress of the struggle, conducted with the pieces on the board), in which stream (of consciousness) all the aspects described in the previous paragraph are embedded (referred to the respective agent-subject) - this might be all that goes on in the minds of Chess-White and Chess-Black, respectively. But it might also be not all: What if Chess-White and Chess-Black, while they are alive and not infrequently have some free time at their disposal (because it takes a while before the opponent makes his next move in the struggle they find themselves engaged in)-what if they each like to speculate about matters which they do not have the means of acquiring proper knowledge about?

Suppose they do like to speculate (and do not only function); they have this reflective and self-reflective impulse that makes each of them wonder about the world (that is, what is to them the world) and their situation in it, and the ultimate truth about it all (which may even include the considerable magnanimity of treating the opponent as one's metaphysical equal). It may surprise some of us spectators from the outside (who still are in the transcendence of $g$, even after the immanence of $g$ has -in the fantasy of a thought-experiment-been broadened), and some it may not surprise, that the speculations of Chess-White and Chess-Black lead to different results. I don't know whether the difference in results has anything to do with one of the two being on the winner's street, the other on the loser's; I don't even know which speculation-result comes from which one of the two. But here are the two results:

I. "The board and the pieces and, in fact, we ourselves who consist of the pieces and live in them have been made by someone who can do things that we, Chess-Black and Chess-White, cannot even dream of doing; and this same all-powerful One has also pitted us here, on the board, one against the other. He ordained laws for our doings which we cannot break, which, however, also leave ample room for each of us to make our own choices. We, Chess-Black and Chess-White, whether we win or lose, will die sooner or later. But the all-powerful One will resurrect us into a new struggle, each against the other, on this same board with these same pieces. In the end, at the last resurrection, there will be no more struggles, the all-powerful One will have mercy on us and we shall live in eternal peace."

II. "Neither the board nor the pieces nor we who consist of the pieces and live in them have been made by anyone; for there is nothing except us, this board and the pieces, and the struggle, and the uncreated inexorable laws which ordained it. In this struggle, nothing is due to choice, everything is predetermined. Our prevalent consciousness of having a choice is entirely illusory; it is due to the fact that we do not know all the laws that rule our doings. Yet, in most of our doings (that is, as long as we do not get into 'the dire straits') we are free, because in most of our doings precisely that happens what we want (and will) to happen, believing, after deliberation, that it is the relatively best for us on the occasion. We, Chess-Black and Chess-White, whether we win or lose, will die sooner or later, happily or unhappily, just as the Laws decree. And when we die, this will be the end of it all. It is a good thing: the end of it all."

\section{Lessons}

What is the point of all this? The point is, of course, that, from the philosophical (epistemological and ontological) point of view, the metaphysical situation of Chess-Black and Chess-White and their world is essentially like the metaphysical situation of us and our world.

Neither Speculation (I) nor Speculation (II) hits on the entire metaphysical truth about Chess-Black and Chess-White and their world, but Speculation (I) is clearly much closer to the truth than Speculation (II). Thus, the first lesson to be learned (if anybody these days still needs to learn it-but logical empiricism and Wittgensteinianism are not quite dead yet) is this: Nothing rationally forbids that there is a metaphysical truth, expressible in cognitively meaningful sentences, although this truth cannot 
be known-cannot be known in a sense: it certainly can be known if knowledge is simply taken to be true belief.

The second lesson to be learned is this: In metaphysical theory, denying ontological transcendence is not in itself rationally better than assuming it; denying ontological transcendence is, in itself, just as much a step beyond epistemological immanence-a step into the (in a sense) unknown-as is assuming ontological transcendence. More generally speaking, of two metaphysical theories, the one which is ontologically simpler is not ipso facto—simply qua simpler — closer to the metaphysical truth than the one which is less simple ontologically. ${ }^{7}$

The third lesson to be learned is this: The conception of libertarian (hence incompatibilist) free will is, from the metaphysico-epistemological point of view, neither inconsistent nor incoherent, nor less rational than rivaling conceptions. This is true although what is said in Speculation (I) is not quite true (given the model): it is said there (indirectly) that Chess-Black and Chess-White each make-and therefore, first of all, have - their own choices. In reality, it is the player behind (or rather, beyond) Chess-Black and the player behind (beyond) Chess-White who first have and then make these choices (each player making his own choices, each being not determined—only guided—by the rules of Chess). Chess-Black and Chess-White are merely the ultimate addressees for carrying out the choices that are being made. In this function, they are far from mindless: the conscious processes in the players that lead up to the making of the choices are being copied, in their essentials, into the consciousnesses of Chess-Black and Chess-White, respectively, and the limbs of each are being moved accordingly-not by Chess-Black or Chess-White but by the (hands of the) respective players behind them. Chess-Black and Chess-White do not have an inkling of this reality (but it is certainly not impossible that at some stage of $g$ their speculative minds will touch on the whole metaphysical truth about them).

The fourth lesson to be learned is this: The conception of a world-creator is, from the metaphysico-epistemological point of view, neither inconsistent nor incoherent, nor less rational than rivaling conceptions. For Speculation (I) can easily be perfectly correct in what it says about "the all-powerful One." Suppose game $g$ is in fact not played by two players, but only by one. Suppose Robinson Crusoe, while alone on his island, made a Chess board and Chess pieces; in fact, he made the board of Chess-Black and Chess-White, and Chess-Black and Chess-White themselves-he even called them that way-and determined rules for the specific board game (qua type) he had in mind; he did so by writing down the rules of Chess from memory. He got into the habit of playing Chess against himself and of endowing, while doing so, Chess-Black and Chess-White with separate personalities and consciousnesses-personalities and consciousnesses as befitted their natures as sets of Chess pieces on a Chess board. As a luxury, he gave Chess-Black and Chess-White each a penchant for metaphysics-in fact, penchants for fundamentally differing metaphysical world-views. To his delight, Robinson found out that he had the power of making his Chess-fantasies real, and of course he frequently exercised this power for his amusement in his loneliness. One of the games (qua concrete token) Robinson played was $g$; and many, many games with the pieces and the board he had made were played by him after $g$, Chess-Black and Chess-White being resurrected on each occasion. ${ }^{8}$ When Robinson finally left the island he took the pieces and the board with him, but never again used them. At home, he put the board on a table and set the pieces on the board, as if ready for action-and thus they remained and are today in the Maritime Museum in XYZ, behind plate glass, Chess-Black and Chess-White standing on the board at eternal peace (but not dead!).

7 Why do so many people think otherwise? Presumably because they assume from the start that certain substantial metaphysical theories are true or more likely to be true, which theories happen to be ontologically simple. But if this is the case, then, of course, one's belief in ontological simplicity as an indicator of metaphysical truth is already founded on one's substantial metaphysical beliefs, and, on pain of vicious circularity, the former belief cannot serve as support for the latter beliefs.

8 I leave it open whether they remembered their previous lives or not. 
The fifth and final lesson to be learned is this: From the metaphysico-epistemological point of view, the occurrence of miracles is not something to be rationally discounted. For who is more powerful, Robinson or the rules of Chess? Suppose that, in fact, in game $g$, Chess-White makes a move which is contrary to the rules of Chess, a move Robinson fully intended. Both Chess-Black and Chess-White are highly astonished; given their beliefs about the ways of "the world," they did not expect this and cannot explain it. Then the game continues, and all is back to normal. Is there anything in the inexplicable event-inexplicable only for Chess-Black and Chess-White-to be balked at in the name of reason and rationality?

It is illuminating to see how Chess-Black and Chess-White integrate the inexplicable event into their respective metaphysical speculations. I offer three options for an addition to Speculation (I), and three for an addition to Speculation (II):

(I.I) "The all-powerful One once intervened, departing on that occasion from the laws he ordained. He did so in order to show favor to me, disfavor to my opponent, and his power to both of us, strongly reminding us-but particularly my opponent-that he exists."

(I.II) "The all-powerful One once intervened, departing on that occasion from the laws he ordained. He did so in order to show disfavor, in particular to me, and his power to both of us, strongly reminding us—but particularly me-that he exists."

(I.III) "The all-powerful One once intervened, departing on that occasion from the laws he ordained. He did so in order to show his power to both of us, strongly reminding us that he exists, so that we may not despair of being saved by him one day."

(II.I) "What occurred does not show that the Laws can be broken; it only shows that the Laws are more complex than we can ever understand."

(II.II) "What occurred does not show that the Laws can be broken; it only shows that the Laws do not exclude freak events from happening. Accepting this, I do have to revise my original position: I no longer hold that the Laws determine everything; I now believe that the Laws and absolute Chance determine everything."

(II.III) "Did this weird event really happen? Sober reflection in the light of uniform experience before its supposed occurrence and afterwards shows that the likelihood of its having really happened is zero. The memory-image I have of it must be illusory. My opponent-he, indeed, believes it happened. This fact, however, is easily explainable: given his religious outlook, he more or less must believe that it happened."

Of these six speculative reactions to the inexplicable event, the reactions that are natural additions to Speculation (I) are closer to the metaphysical truth about Chess-Black and Chess-White than those that are natural additions to Speculation (II). Clearly, the former reactions deserve no less intellectual respect than the latter. Yet, in real life-in real-life philosophy-accepting miracles usually makes one the butt of intellectual contempt. Metaphysical modelling, as here provided, should contribute to showing that this attitude of contempt is epistemologically unconscionable-at least when one is doing metaphysics and dealing with ultimate questions. The issue of miracles unmistakably points to just such a question: It is an ultimate question whether the first basis of world-explanation is constituted by absolute, self-standing laws, or rather by an absolute, self-standing law-maker-who, as law-maker, can also be an occasional law-breaker. ${ }^{9}$ The epistemological insight I would like to urge is that there is more than one rationally permitted — therefore rationally respectable — answer to every ultimate question, and in particular to the question just broached. Thus, regarding ultimate world-explanation, belief in God is certainly not more rational than belief in absolute natural laws; the same, however, holds true vice versa: belief in absolute natural laws is not more rational than belief in God. Note that the intellectual disdain many people feel for the God-answer to the question of first principles-for the answer they

9 He can also be a frequent law-breaker, even a law-breaker all the time. But laws are certainly not made for being frequently or always broken. 
believe to be false — cannot be justified by invoking natural science; for natural science—as long as it strictly remains natural science-is not interested in ultimate questions, and not interested in answers to them. Natural science is content with finding regularities in the world which, although one has tried hard several times, have not been disproven by state-of-the-art experiments, but have, on the contrary, been corroborated by them. And natural science is fully content if these regularities are describable in mathematical terms with mathematical precision; speculating about their ultimate, their metaphysical import is not the task of natural science, and not a task it would or should like to have.

\section{Foundations and objections}

It is an egregious misunderstanding if the expositions in the preceding section are taken to be meant as arguments for free will and a creator-god, for immortality and for miracles. No such thing was intended. Rather, the intention was to show by metaphysical modelling (that is, by the construction of smaller and simpler analogs of the metaphysical—more precisely speaking, the metaphysico-epistemological—reality) that belief in free will, a creator-god, immortality, and miracles is so far from being "incoherent", "inconsistent," or "irrational" as to be no less rational than belief in the denial of free will, the denial of a creator-god, the denial of immortality and of miracles. The aim was to demonstrate-in the face of widespread contrary opinion-the parity in rationality of all of these metaphysical beliefs, be they affirmative or negative. The larger aim was to display the cognitive outlook which is epistemologically appropriate for metaphysical belief, and therefore also for metaphysical knowledge: When we search for truths that are specific to the realm beyond epistemological immanence, affirmative or negative ones, we ought to be epistemologically reflective and honest enough to know that finding those truths, if we find them, will not be due-cannot be due - to our rationality and intelligence. The lumen naturale (as it is traditionally called), reason has no power to establish as rationally obligatory belief in any proposition, affirmative or negative, which is specific to the realm beyond epistemological immanence; all it can do is to show that belief in such a proposition is rationally permitted - just as the opposite belief is rationally permitted. As the history of philosophy shows, this epistemologically salutary (and essentially Kantian) stance is from time to time forgotten (as it seems to be in our time) and needs to be called to mind, which can very well happen in the guise of defending the rational permissibility - not the rational obligatoriness - of metaphysical beliefs that are widely held to be irrational within the philosophical community; which, in fact, are regarded as an intellectual disgrace there.

Metaphysical modelling is a thought-experimental procedure which works per analogiam; it employs inference by metaphysical analogy, of which the general schema is this:

\section{Inference by metaphysical analogy}

Just as situation $X$ is the situation of certain entities [for example, of Chess-White and Chess-Black in their world] and proposition $\mathrm{Y}$ is the truth about this situation, so $\mathrm{X}^{\prime}$ is the situation of certain other entities [for example, of us human beings in our world], and proposition $Y^{\prime}$ may, with integrity of reason (salva integritate rationis), be held to be the truth about this other situation.

For making - in accordance with the above schema-an inference by metaphysical analogy (and be rationally justified in doing so), the following (schematic) presupposition must be fulfilled; from that presupposition it is also apparent why the above inference schema is called "inference by metaphysical analogy":

\section{The presupposition of inference by metaphysical analogy}

$X$ and $X^{\prime}$ stand in a relation of metaphysically substantial similarity to each other, and so do $Y$ and $Y^{\prime}$, including the fact that the relationship between $Y^{\prime}$ and $X^{\prime}$ is in the metaphysical respect substantially similar to the relationship between $\mathrm{Y}$ and $\mathrm{X}$. 
Thus, if one wishes to criticize the metaphysical modelling here presented, a possible objection would be to assert that the necessary presupposition for making the inference by analogy contained in that modelling is not fulfilled.

But how would one substantiate this assertion? It is true that a Chess board is, in a way, not much like space, and that the stages of Chess game $g$ are, in a way, not much like time, and that Chess-Black and Chess-White and their doings are, in a way, not much like human beings and their doings. It is also true that the rules of Chess are, in a way, not much like the laws of nature we learn from science. But it seems also to be true that the obvious dissimilarities between the intended partners-in-analogy are metaphysically irrelevant, whereas the similarities are metaphysically substantial enough to allow drawing the analogy in metaphysics which was in fact drawn.

Another possible objection would be this: "Let it be conceded that one can rationally draw the analogy in metaphysics that was in fact drawn. But all that is shown by this is a logical possibility: it is logically possible that, metaphysically, it is with us in our world and beyond, as it with Chess-Black and Chess-White in their Chess-world and beyond. So what? There are other logical possibilities, and rather more plausible ones. And do we need a fantastic story about a Chess-world, featuring conscious bodies that consist of Chess pieces, in order to admit the logical possibility that our world might be a game played by a transcendent god for his own amusement, according to rules he makes or breaks as he thinks fit, with us being mere instruments of his unbounded power and will? Absolutely not."

The answer to this objection is this: What was shown by the expositions in the preceding section is more than that a certain complex state of affairs is a logical possibility: what was shown is that it is an epistemologically rational possibility. Every epistemologically rational possibility is, and has to be, a logical possibility, but the converse is not true. An epistemologically rational possibility is a logical possibility which is such that its actuality has-if considered in an epistemologically adequate way - a rational degree of credibility (i.e., of doxastic probability) that is not smaller than the rational degree of credibility accorded to the actuality of any logical possibility seriously competing (not merely incompatible) with it. ${ }^{10}$ Thus, it is indeed true- to quote the objector-that "there are other [i.e., other and seriously competing] logical possibilities"; but it is not true that they are "more plausible." If an epistemologically adequate attitude is maintained, which fully takes into account as metaphysical the metaphysical contents of the other and seriously competing logical possibilities, then the expositions in the preceding section do show that the actuality of each of these other, seriously competing possibilities is, though not less rationally plausible, also not more rationally plausible- not more rationally credible - than the actuality of the particular logical possibility that has, no doubt, been accorded special attention in the here-presented metaphysical modelling: the logical possibility whose actuality is favored by the particular thought-experimental story here told.

This latter possibility is an epistemologically rational possibility. It is, however, not the one I believe to be the actual(ized) one among the seriously competing logical possibilities in the metaphysics of the world-God relationship. The one I believe to be the actual one (the one that is actual) among these possibilities, all of which are epistemologically rational, has not, as yet, been fully described here. It is in all respects like the logical possibility whose actuality is favored by the particular thought-experimental story here told-except for one important respect: In that story, Chess-Black and Chess-White, though conscious and intelligent, are mere instruments of Robinson; accordingly, the logical possibility whose actuality is favored by the here-told thought-experimental story has it that we are mere instruments of God. I do not believe that we are mere instruments of God; I

10 A logical possibility is a state of affairs which is logically possible. The actuality of a logical possibility-that is, of a state of affairs which is logically possible - is the state of affairs that the logical possibility (the one in question) is actual, meaning: that the logically possible state of affairs (the one in question) is actual. Note that a logically possible state of affairs $p$ is not identical with the state of affairs that $p$ is logically possible. In contrast, $p$ can be taken to be identical with its actuality, that is, with the state of affairs that $p$ is actual. It does not follow from this identity that $p$ is actual; for this, the actuality of $p$ must itself be actual (which, normally, is far from being automatically guaranteed). 
believe that we act—at least sometimes and partly-on our own. Moreover, contrary to what the here-told thought-experimental story suggests, I do not believe that God, if he acts, needs to act via us as instruments; he does act in this way, I believe, but I also believe that God has many more ways of acting at his disposal-miraculous ones and non-miraculous ones-than acting via us as instruments.

It is important to note: For being a good model of our metaphysico-epistemological situation, what is presented as the metaphysical truth about what is actual in the model need not analogically correspond one-to-one to what the maker of the model, or to what anybody else, believes to be the metaphysical truth about what is actual in reality; in other words, the ultimate truth about Chess-Black and Chess-White (their situation) need not match what I, or what other people, believe to be the ultimate truth about us (our situation). For we cannot know, in an intersubjectively justified way, what is the ultimate truth about us (although I-the maker of the model—may very well be right in what I believe that truth to be). The ultimate truth about Chess-Black and Chess-White, a determination of which is needed for making the model complete, can, therefore, be some expectable or not so expectable free product of the imagination, as long as the analog of a seriously competing metaphysical possibility is being imaginatively produced (as is here the case). It seems epistemologically quite appropriate that the metaphysical truth about what is actual in the model should not be a matching analog of what the maker of the model believes to be the metaphysical truth about what is actual in reality: he does not know nor claims to know more than anybody else.

\section{Defending and clarifying analogical thinking in metaphysics}

Metaphysical modelling is one way in which analogical inference-the drawing of analogies-can serve an epistemologically adequate understanding of metaphysical claims. There are other ways. Here, below, follows a famous example-which, unfortunately, is very often not correctly understood (by proponents and opponents alike). Scrutinizing this example will also be of help for understanding metaphysical modelling: what it aims to do and can do, and what it cannot do and does not aim to do.

\section{A well-known instance of inference by metaphysical analogy}

Just as the existence of this watch is the situation of this watch-situation $X$-and the proposition that a human being made this watch-proposition $\mathrm{Y}$-is the truth about this situation, so the existence of this world is the situation of this world-situation $\mathrm{X}^{\prime}$-and the proposition that this world was made by a maker with superhuman power and intelligence-proposition $Y^{\prime}$-may, with integrity of reason, be held to be the truth about this other (the second-mentioned) situation.

This, indeed, is a well-known inference by metaphysical analogy-and an inference which is repudiated not only by those who, confronted with it, just cannot accept that this world was made by a maker with superhuman power and intelligence (who usually believe that it came into being automatically- "self-movedly," or that it has existed and will exist in a self-standing manner forever); it is repudiated nowadays also by many of those who do, on the contrary, accept the "creationist" proposition in question. ${ }^{11}$ In order to obviate a fundamental misconception one may have concerning the nature of the inference, it must be pointed out that its conclusion is not that this world was made by a maker with superhuman power and intelligence; the conclusion is merely that it may, with integrity of reason, be held to be true that it was made by a maker with superhuman power and intelligence; in other words, that its being made by such a maker is an epistemologically rational possibility.

Will this help to mitigate the widespread disdain? Not always. Often not, I am afraid-not even when it is not only conceded (as it must be) but also emphasized that the actuality of any logical possibility which is seriously competing (in metaphysics) with the superhuman-maker-possibility is, though not more rationally credible, also not less rationally credible than the actuality of this latter

11 They do not want the purity of their heroic religious faith sullied by any conceited pretensions of human rationality. 
possibility. However, a continuation of disdainful rejection requires rational justification-at least if the rejectors claim to be philosophers. One way of rational criticism would be to show that the necessary presupposition of the above inference by analogy is not fulfilled. Do situations $X$ and $X^{\prime}$ really stand in a relation of substantial metaphysical similarity to each other? And is this also true of propositions $Y$ and $Y^{\prime}$ ? Is it really true that the relationship between $Y^{\prime}$ and $X^{\prime}$ is in the metaphysical respect substantially similar to the relationship between $Y$ and $X$ ? The answers to these questions are crucial. Let's answer these questions.

Concerning situations $\mathrm{X}$ and $\mathrm{X}^{\prime}$ : The existence of the world and the existence of the watch are in many respects dissimilar situations; however, a substantial metaphysical similarity between them is this: both the existence of the world and the existence of the watch is an existence of a highly complex functioning whole with many parts working together in a strictly organized manner.

Concerning propositions $\mathrm{Y}$ and $\mathrm{Y}^{\prime}$ : That the watch was made by a human maker is an agent-causal proposition explaining, if true, the existence of the watch. That the world was made by a maker with superhuman power and intelligence is an agent-causal proposition explaining, if true, the existence of the world. Clearly, there is a substantial metaphysical similarity between the two propositions.

Concerning the relationship between $\mathrm{Y}^{\prime}$ and $\mathrm{X}^{\prime}$ vis-à-vis the relationship between $\mathrm{Y}$ and $\mathrm{X}$ : Both the relationship between $Y^{\prime}$ and $X^{\prime}$ and the relationship between $Y$ and $X$ are causally explanatory relationships: $Y$, if true, causally explains $X$, and $Y^{\prime}$, if true, causally explains, $X^{\prime}$. $Y$, moreover, is a good causal explanation of $X-$ of the existence of the watch-in view of the fact that the watch is a highly complex functioning whole with many parts working together in a strictly organized manner: a fittingly (namely, humanly) intelligent and powerful agent can very well be what brought the watch into existence. And, likewise, $Y^{\prime}$ is a good causal explanation of $X^{\prime}-$ of the existence of the world - in view of the fact that the world is a highly complex functioning whole with many parts working together in a strictly organized manner: a fittingly intelligent and powerful agent can very well be what brought the world into existence. Since the world is so much more complex-infinitely more complex-than the watch, and since, unlike the watch, the world far transcends the sphere of human purposes, such an agent-a world-maker (not merely a watch-maker)—has to be superhumanly intelligent and powerful. Thus, there can be no doubt: the relationship between $Y^{\prime}$ and $X^{\prime}$ is in the metaphysical respect substantially similar (proportionally similar) to the relationship between $\mathrm{Y}$ and $\mathrm{X}$.

The necessary presupposition of the above well-known inference by metaphysical analogy is, therefore, fulfilled in its entirety; hence that inference can (rationally) be drawn, yielding the conclusion that it may with integrity of reason be held to be the truth that this world was made by a maker with superhuman power and intelligence.

It is true: With integrity of reason one may also hold it to be the truth, say, that this world is self-standing and self-moving, and has existed and will exist in this manner forever. That this metaphysical belief-metaphysical naturalism ${ }^{12}$-is rationally permitted is simply due to the metaphysico-epistemological situation we are in-the metaphysico-epistemological situation which, I hope, has here been made vividly palpable by metaphysical modelling, in particular, by the philosophical fable about Chess-Black and Chess-White. This same philosophical fable also shows that, from the metaphysico-epistemological point of view, metaphysical naturalism is, though rationally permitted (i.e., rational in the weak sense), not rationally obligatory (not rational in the strong sense).

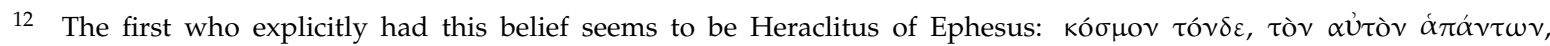

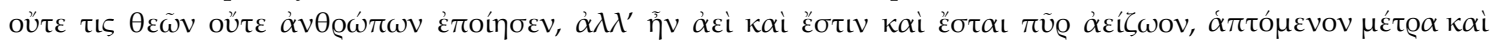

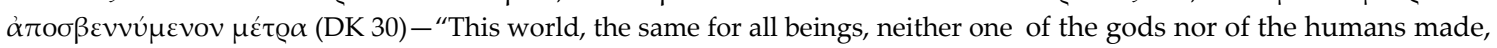
but it was always and is and will be an ever-living fire, lighting itself according to measures and extinguishing itself according to measures." (Translation UM.) Note that Heraclitus is a metaphysical naturalist without being a materialist (at least, he is not a materialist in the modern, "mindless" sense). Materialism is not a necessary component of metaphysical naturalism; metaphysical naturalism is perfectly compatible with a pantheistic and panpsychistic outlook (for example). 
If, contrary to this insight, metaphysical naturalism is held to be not only rationally permitted but also rationally obligatory (which is a rather common implicit or explicit opinion), then such an attitude is not the rational consequence of the enlightenment brought about by natural science. It is often the effect of an epistemologically unreasonable dogmatism, of a cognitive overconfidence-frequently fueled by a hatred of "religion," and brash and insolent in its expression-which does not know (nor wants to know) where the relative certainty of natural science ends and the true uncertainty of metaphysics begins, an overconfidence as far removed from being touched by (broadly) Kantian wisdom as it can possibly be.

But would it not be better-precisely in view of Kantian wisdom - to abstain from doing any metaphysics at all? It would not be better. Metaphysical modelling makes it plain that there is a rich realm of metaphysical propositions, all of which are either true or false. This rich realm of propositions offers much for us to discover; it offers much for us to clarify and to make precise, much to explore in its logical consequences, much to organize into consistent systems, much to distinguish, contrast, oppose, in other words: much to consider in its various relationships with beings of the same category (the category of propositions) and with beings of other categories (individuals, properties, relations, states of affairs, etc.). More importantly, this rich realm of propositions offers much for our affirmation or denial; if our affirmations and denials are true to the metaphysical facts, then these acts of belief are pieces of metaphysical knowledge-are knowledge at least in the minimal sense. Most importantly, this rich realm of propositions comprises propositions which, if true (and also if false), are of utmost consequence for our "ultimate nature and fate." There is no reason why we-we human beings—should not do metaphysics, and deal with metaphysical propositions not religiously, not mythologically, but philosophically.

Funding: This research received no external funding.

Conflicts of Interest: The author declares no conflict of interest.

\section{Reference}

Meixner, Uwe. 2010. Modelling Metaphysics. The Metaphysics of a Model. Heusenstamm: Ontos (now De Gruyter). 